\title{
苯炔对双键插入反应的研究进展
}

\author{
吴春芯 ${ }^{a}$ 杨玉坡 ${ }^{b}$ 史 峰*,a \\ ( ${ }^{a}$ 河南大学 河南省天然药物与免疫工程重点实验室 开封 475004) \\ ( ${ }^{b}$ 青岛科技大学化学与分子工程学院 青岛 266042)
}

\begin{abstract}
摘要 苯炔对双键的插入反应是近年来苯炔化学的一个热点领域. 苯炔对双键插入将产生一个邻亚甲基醌型中间体, 后者和苯炔一样是有机反应的重要活性中间体之一. 综述了近年来苯炔对双键的插入反应及其在合成化学中的应用, 并力图从反应机理的角度对这些插入反应及其生成的中间体进行结构上和反应活性上的阐释.

关键词 苯炔; 邻亚甲基醌; 活性中间体; 周环反应; 串联反应
\end{abstract}

\section{Recent Advances in Aryne Double Bond Insertion}

\author{
Wu, Chunrui ${ }^{a} \quad$ Yang, Yupo $^{b} \quad$ Shi, Feng*,a
}

( ${ }^{a}$ Key Laboratory of Natural Medicine and Immuno-Engineering of Henan Province, Henan University, Kaifeng 475004)

( ${ }^{b}$ College of Chemistry and Molecular Engineering, Qingdao University of Science and Technology, Qingdao 266042)

\begin{abstract}
Aryne double bond insertion generates an ortho-quinomethide-typed intermediate, which, like aryne itself, is one of the most important reactive intermediates in organic reactions. This review summarizes recent advances in this field and the potential applications in synthetic organic chemistry, with a focus on the reaction mechanism, as well as the structure and reactivity of the ortho-quinomethide intermediates.
\end{abstract}

Keywords aryne; ortho-quinomethide; reactive intermediate; pericyclic reaction; tandem reaction

苯炔是一类具有高活性的有机反应中间体，在有机 合成中有重要的应用 ${ }^{[1]}$. 苯炔不稳定, 无法分离, 只能 原位产生. 目前, 以 Kobayashi 前体(图 1)在氟离子的作 用下生成苯炔的手段, 因其温和有效且可以通过改变氟 源、温度、溶剂等条件来控制苯炔产生的速度等优势, 得 到了广泛的使用 ${ }^{[2]}$. 苯炔结构中的不稳定参键可以参与 多种反应, 如[3+2]偶极环加成、[4+2] Diels-Alder 环加 成、亲核加成、碳一碳和碳一杂原子单键的插入等. 本文 将对苯炔对双键的插入反应进行总结.

由于苯炔环内参键的张力及其低能量的最低末占 有分子轨道(LUMO)的缘故, 苯炔在无过渡金属催化的 条件下容易被亲核试剂进攻, 生成芳基负离子, 该芳基 负离子随后可作为新的亲核试剂进攻外部的亲电试剂, 发生加成反应生成邻二取代苯. 作为一种特殊情况, 当 外部分子的亲核部分与亲电部分通过单个 $\sigma$-键连接在 一起时, 该 $\sigma$-键即在反应中断裂, 发生苯炔的单键插入
反应 ${ }^{[3]}$. 与单键插入相比, 苯炔对双键插入的研究比较 少. 该反应也是一个两步反应(Scheme 1), 首先是苯炔 与电子极化的双键发生分步的 $[2+2]$ 环加成反应, 生成 苯并四元环中间体; 由于环张力的作用, 该四元环在一 定的条件下可以发生逆 $4 \pi$ 电环合反应, 生成另一高活 性的邻亚甲基醌型中间体 $o-\mathrm{QM}^{[4]}$. 文献 ${ }^{[4]}$ 表明, 四元环 上带的取代基给电子能力越强, 则四元环越容易开环 (机理有所改变). 邻亚甲基醌型中间体也不稳定, 可以 继续发生一系列不同类型的反应，例如 $[4+2]$ 的 Diels-Alder 环加成反应, $6 \pi$ 电环合反应、亲核加成反应 等.

\section{1 苯炔对碳碳双键的插入反应}

由于苯炔的亲电性，能够与苯炔发生反应的碳碳双 键必须是富电子、有亲核性的. 苯炔与普通碳碳双键的 $[2+2]$ 环加成反应通常伴随竞争的烯反应(ene reaction),

\footnotetext{
* E-mail: fshi@henu.edu.cn
}

Received November 26, 2014; revised December 15, 2014; published online January 9, 2015.

Project supported by National Natural Science Foundation of China (No. 21002021) and the Program for Science \& Technology Innovation Talents in Universities of Henan Province (No. 13HASTIT010).

国家自然科学基金(No. 21002021)和河南省高校科技创新人才支持计划基金(No. 13HASTIT010)资助项目. 


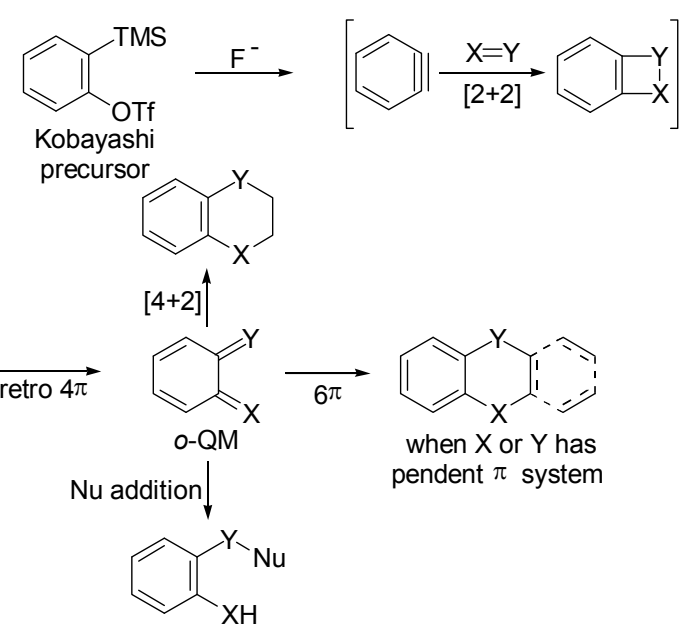

图式 1 苯炔对双键的插入反应及可能的后续历程

Scheme 1 Aryne double bond insertion and subsequent processes

产率较低而且得到混合物, 应用价值不高 ${ }^{[5]}$.

典型的富电子碳碳双键包括烯醇、烯胺及其类似的 官能团. 其中, 相当于羰基 $\alpha$-位的碳原子作为亲核试剂, 相当于羰基的碳原子作为亲电试剂. 苯炔对烯醇碳碳双 键的插入反应早期被综述过 ${ }^{[6]}$, 因最近并无太大发展, 本文不再重复叙述.

作为烯醇衍生物的特例, 硅基取代的烯酮缩酮(silyl ketene acetal)属于一类稳定的烯醇硅醚衍生物. Suzuki 课题组 ${ }^{[7]}$ 发现在丁基锂的作用下，卤代芳烃通过消除反 应生成的苯炔可以与此类碳碳双键顺利发生 $[2+2]$ 环加 成反应生成苯并环丁酩(Scheme 2), 但是在该反应条件 下并未发生四元环的开环.

$$
\text { OTBS } \frac{n \text {-BuLi }}{T H F,-78{ }^{\circ} \mathrm{C}}
$$

图式 2 苯炔对硅基取代的烯酮缩酮的 $[2+2]$ 环加成 Scheme 2 Aryne [2+2] cycloaddition with silyl ketene acetals

苯炔与烯胺的反应早在 20 世纪 70 年代就有报道, 但由于当时产生苯炔的条件比较苛刻, 反应的选择性 差, 产率很低 ${ }^{[4,8]}$. 直到 Kobayashi 前体的广泛应用, 苯 炔对烯胺碳碳双键的插入反应才迎来了新的发展. 2009 年, Hsung 课题组 ${ }^{[9]}$ 报道了苯炔与烯酰胺的碳碳双键在 $110{ }^{\circ} \mathrm{C}$ 条件下的插入反应. 烯酰胺的碳碳双键首先与苯 炔发生[2+2]环加成反应生成苯并四元环 1 (Scheme 3). 1 可以分离, 也可以在继续加热的条件下开环, 得到双 键插入的邻二亚甲基醌中间体. 当烯酰胺上连有位置合 适的双键时, 此邻二亚甲基醌可以与之发生分子内的 $[4+2]$ 环加成反应生成立体专一的环加成产物(Scheme

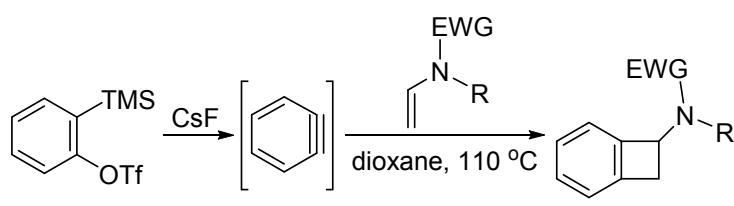

$1,55 \% \sim 95 \%$

EWG $=$ acyl, sulfonyl, ester $\mathrm{R}=\mathrm{Ar}$, Alkyl

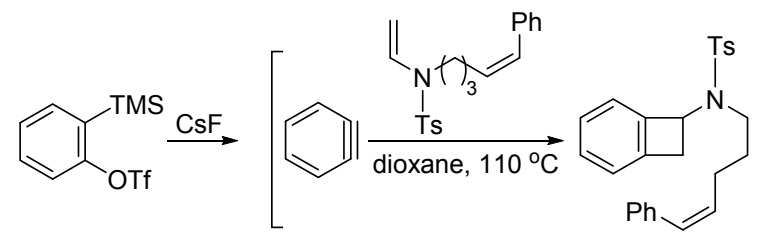<smiles>C=c1ccccc1=CN([Hg])CCCC=Cc1ccccc1</smiles>

$\overrightarrow{[4+2]}$<smiles>[AlH2]N1CCCC2C(c3ccccc3)Cc3ccccc3C21</smiles>

$64 \%$

图式 3 苯炔对烯酰胺碳碳双键的插入/[4+2]环加成串联反 应

Scheme 3 Aryne $\mathrm{C}=\mathrm{C}$ double bond insertion/[4+2] cycloaddition sequence with enamides

3). 该反应给合成氮杂多环衍生物提供了一种立体选择 性好、效率高的新选择. Hsung 课题组 ${ }^{[10]}$ 基于上述反应 过程，实现了天然产物 Chelidonine 和 Norchelidonine 的 高效全合成(Scheme 4).

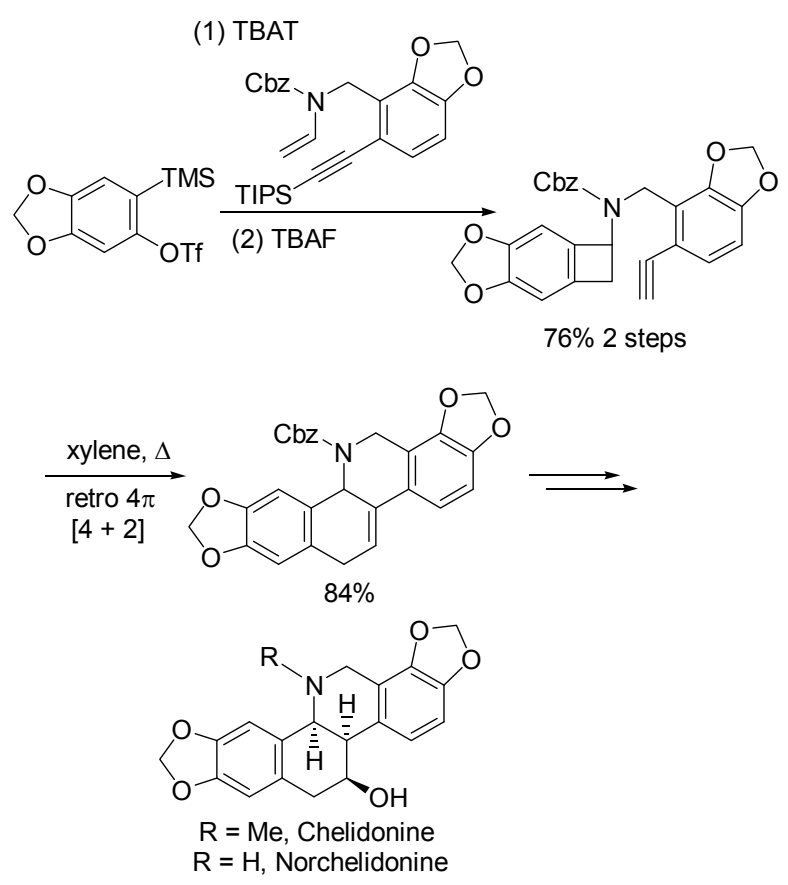

图式 4 苯炔与烯酰胺的反应在全合成上的应用

Scheme 4 Application of aryne/enamide reaction in total synthesis

插烯酰胺是烯酰胺的异构体，由于氨基和酰基对碳 
碳双键电子的推拉作用, 其碳碳双键的极化较普通烯酰 胺更严重. 因此, 插烯酰胺的碳碳双键与苯炔的 $[2+2]$ 环加成反应更容易, 不需加热即可进行. 不过, 苯炔与 插烯酰胺的反应依赖于底物结构, 当氨基氮原子上有氢 取代的时候, 插烯酰胺与苯炔反应, 发生的是 $C$-芳基化 而不是碳碳双键插入 (Scheme 5 $)^{[11]}$. 我们课题组 ${ }^{[12,13]}$ 发 现, 氮原子全取代的插烯酰胺会顺利地与苯炔发生碳碳 双键的插入反应，形成邻二亚甲基醌中间体 2. 与烯酰 胺的这一过程需要 $110{ }^{\circ} \mathrm{C}$ 不同, 插烯酰胺由于其特殊 的推拉电子状态, 相同过程可以在室温发生. 值得一提 的是, 插烯酰胺的推拉电子特征在生成的中间体 $\mathbf{2}$ 上依 然存在, 因此, 2 可以接受亲核试剂(如醇类)进攻而发生 芳构化, 并缓慢水解释放出二级胺得到羰基化合物 (Scheme 5).
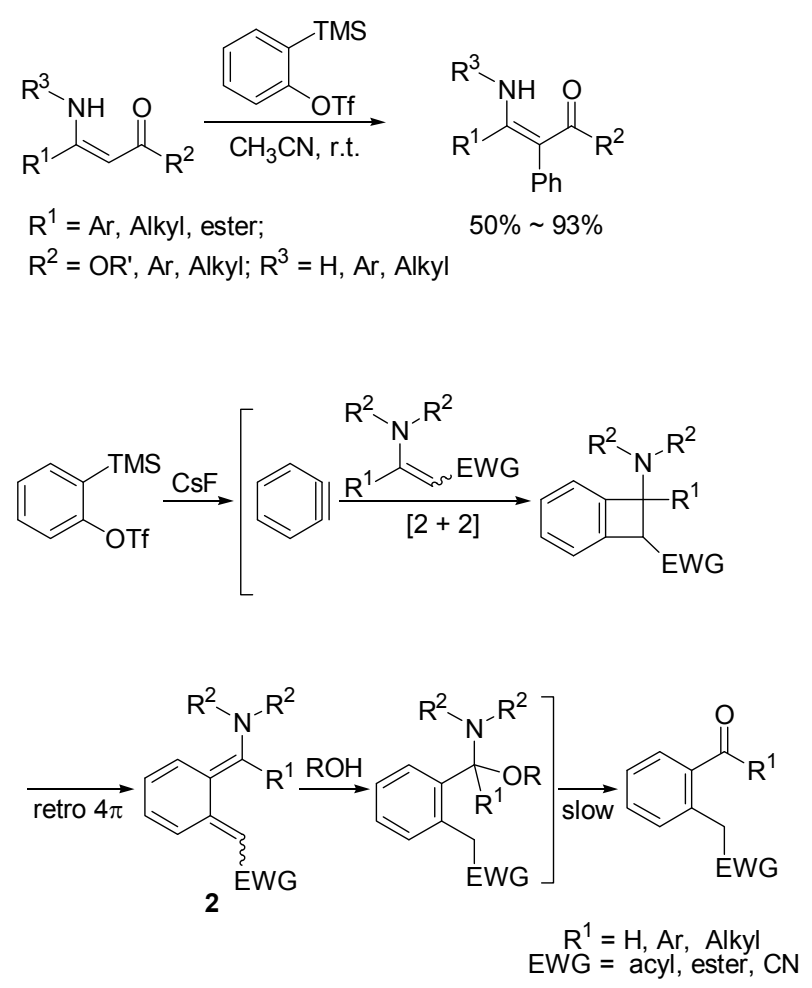

图式 5 苯炔对插烯酰胺碳碳双键的插入/亲核加成串联反应

Scheme 5 Aryne $\mathrm{C}=\mathrm{C}$ double bond insertion/nucleophilic addition sequence with vinylogous amides

\section{2 苯炔对碳氮双键的插入反应}

普遍的说, 碳氮双键的极化程度较碳碳双键高, 其 氮原子作为亲核试剂、碳原子作为亲电试剂与苯炔发生 $[2+2]$ 环加成反应. 早在 1975 年, 即有重氮化邻氨基苯 甲酸在加热条件下生成的苯炔与芳叉苯胺反应的报 道 ${ }^{[14]}$. 后者的碳氮双键与苯炔首先发生 $[2+2]$ 环加成反 应, 生成苯并氮杂四元环, 并开环得到邻亚甲基醌亚胺 型中间体 3,3 可以和另一分子的茮叉苯胺发生 $[4+2]$ 环
加成反应，并水解得到邻氨基苠胺类产品. 但是，该反 应的副反应很多，产率仅有 $18 \%$ (Scheme 6). 类似的反 应还在双亚胺体系中得到了应用 ${ }^{[15]}$, 但依然缺乏选择 性和合成价值.

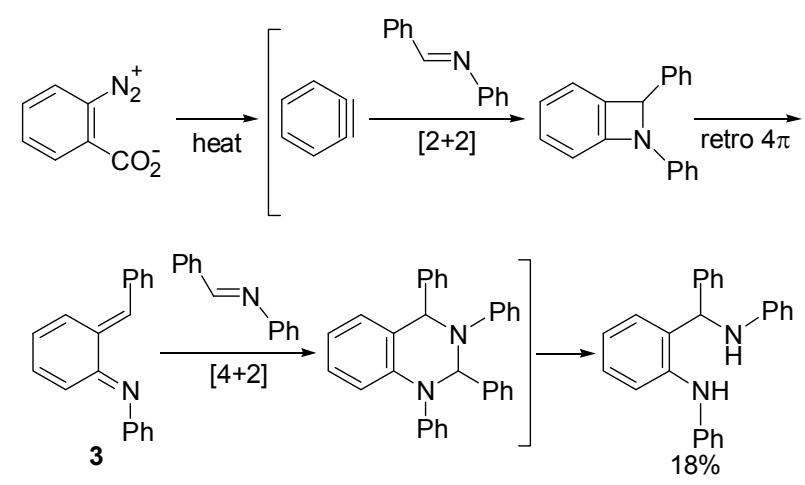

图式 6 苯炔对普通亚胺碳氮双键的插入/[4+2]环加成串联 反应

Scheme 6 Aryne $C=N$ double bond insertion/ $[4+2]$ cycloaddition sequence with imines

此外, 普通亚胺的碳氮双键可能由于碳原子的活性 不足等原因，与苯炔的插入反应有时会停留在氮进攻苯 炔得到的两性离子上 ${ }^{[16]}$. 于是人们开始研究具有更强 亲电性的亚胺. 碳二亚胺、异氰酸酯类的亚胺衍生物是 逻辑上很容易想到的研究对象.

2014 年, 席振峰课题组 ${ }^{[17]}$ 报道了苯炔和碳二亚胺 及端基炔的多组分反应. 该反应中, 苯炔首先与碳二亚 胺的碳氮双键发生 $[2+2]$ 环加成反应生成氮杂苯并四元 环中间体，该中间体在反应条件下开环成邻亚甲基醌亚 胺 4. 此时, 一分子的端基炔作为第三组分对 4 发生亲 核加成并发生芳构化，生成 2-氨基芳基炔基酮亚胺型产 物(Scheme 7). 炔溴和炔碘也能发生反应, 生成溴代或 碘代的产物(Scheme 7), 其机理尚不清楚. 需要指出的 是，该反应只适用于脂肪基取代的碳二亚胺，芳基取代 的碳二亚胺在中间体 4 阶段主要发生与另一个苯炔的 [4+2]环加成，而不是与端基炔的反应.

我们课题组 ${ }^{[13]}$ 也报道了类似的苯炔和碳二亚胺及 亲核试剂的多组分反应. 我们发现, 醇、水、丁二酰亚 胺等亲核试剂可以代替端基炔与中间体 4 发生亲核加 成，生成酰胺、亚胺酯、脒等官能团(Scheme 8). 和席振 峰的报道一样, 我们也发现，只有脂肪基取代的碳二亚 胺可以与苯炔发生上述反应，芳基取代的碳二亚胺只能 得到痕量的产品. 但是, 在相同条件下，与碳二亚胺等 电子的异氰酸酯和异硫氰酸酯不能发生上述过程, 其碳 氮双键无法与苯炔发生插入反应. 对此, 我们尚无法作 出有意义的解释. 

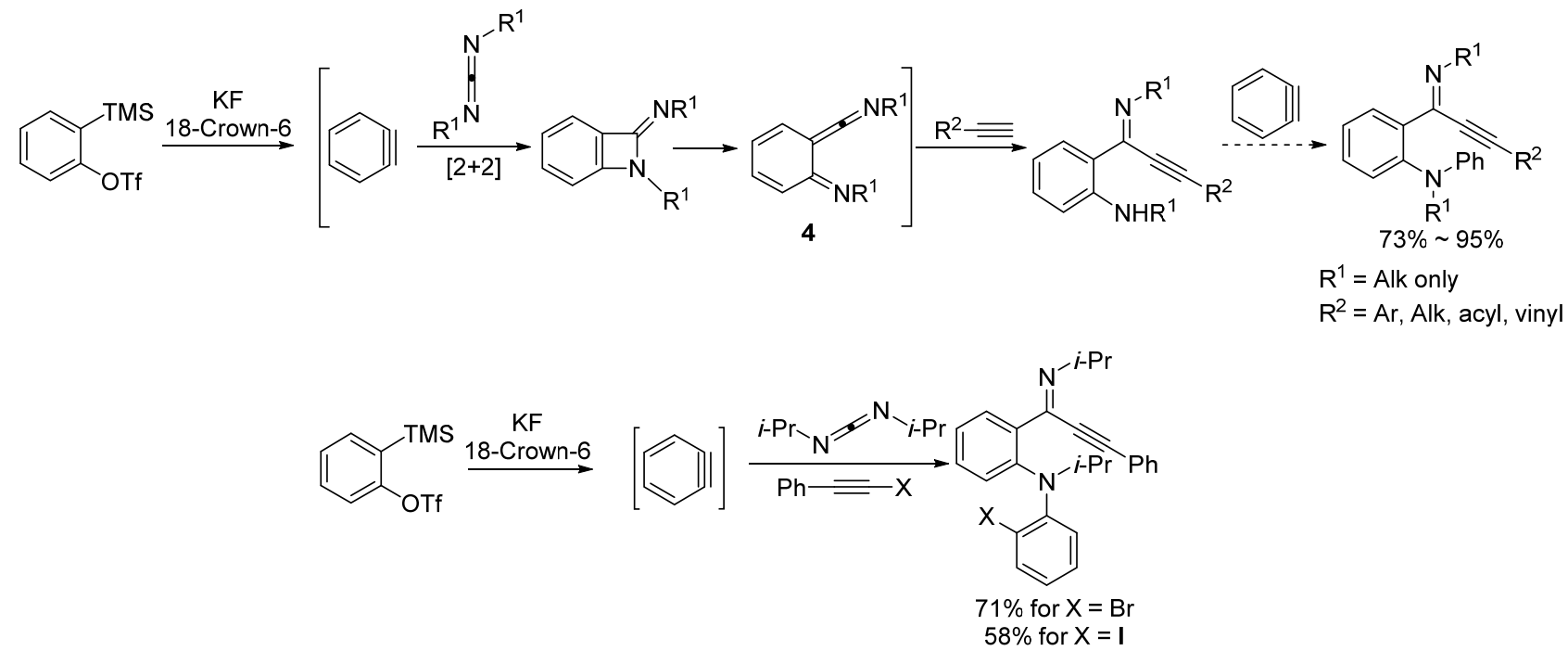

图式 7 苯炔对碳二亚胺碳氮双键的插入/亲核加成串联反应 1: 端基炔作为亲核试剂

Scheme 7 Aryne $\mathrm{C}=\mathrm{N}$ double bond insertion/nucleophilic addition sequence with carbodiimides (1): terminal alkynes as nucleophile

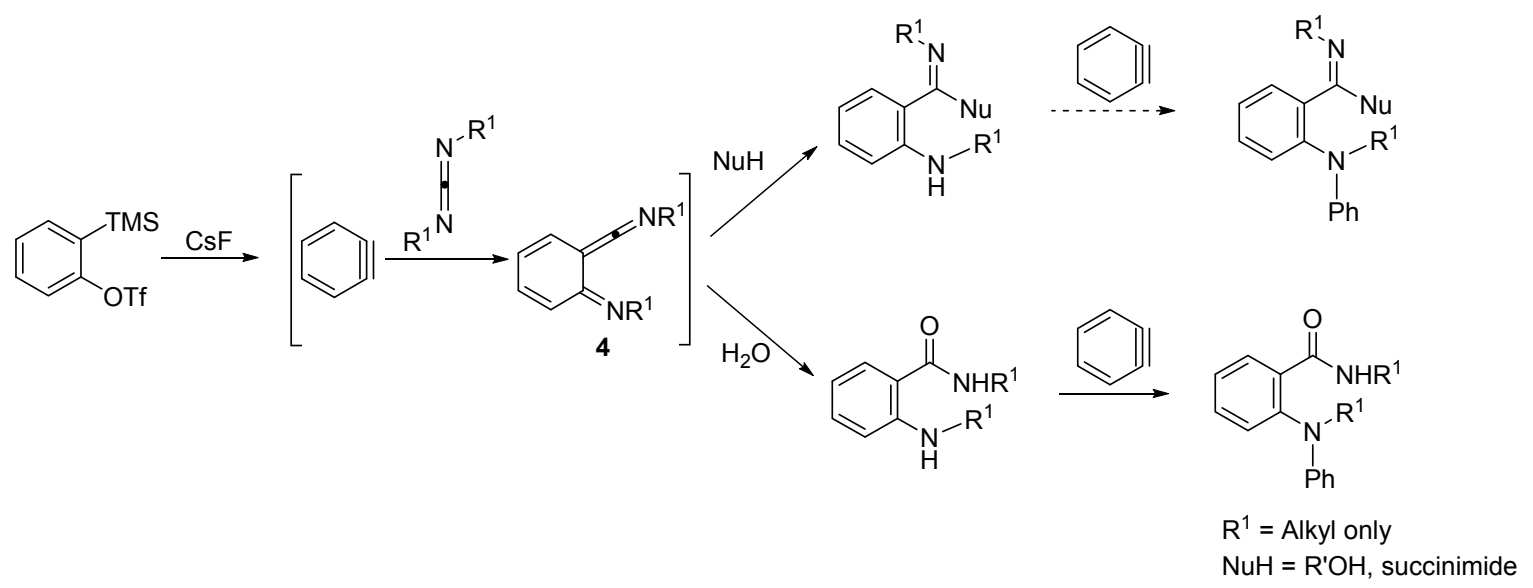

图式 8 苯炔对碳二亚胺碳氮双键的插入/亲核加成串联反应 2: 醇或水作为亲核试剂

Scheme 8 Aryne $\mathrm{C}=\mathrm{N}$ double bond insertion/nucleophilic addition sequence with carbodiimides (2): alcohols or water as nucleophile

与碳二亚胺通过增强碳原子的亲电性获得更好的 反应活性不同，另一类亚胺通过引入环张力来获得更好 的反应活性. Nair 课题组 ${ }^{[18]}$ 在 1975 年报道, 三元环状亚 胺唤丙因( $2 H$-azirine) 的 $\mathrm{C}=\mathrm{N}$ 双键可以与苯炔发生 $[2+$ 2]环加成反应, 生成的四元环由于较大的张力可以自发 重排成吲哚类产品(Scheme 9). 可惜的是, 他们只研究 了 3 个底物, 对反应的适用范围和合成上的应用价值尚 未得出有意义的结论.

\section{3 苯炔对碳氧双键的插入反应}

和碳氮双键相比, 碳氧双键的极化程度更高, 其碳 原子的亲电性更好. 但是, 由于氧原子比氮原子的亲核 性差, 苯炔对羰基的双键插入反应目前存在较大的局限 性，仅适用于部分醛类和甲酰胺的羰基.

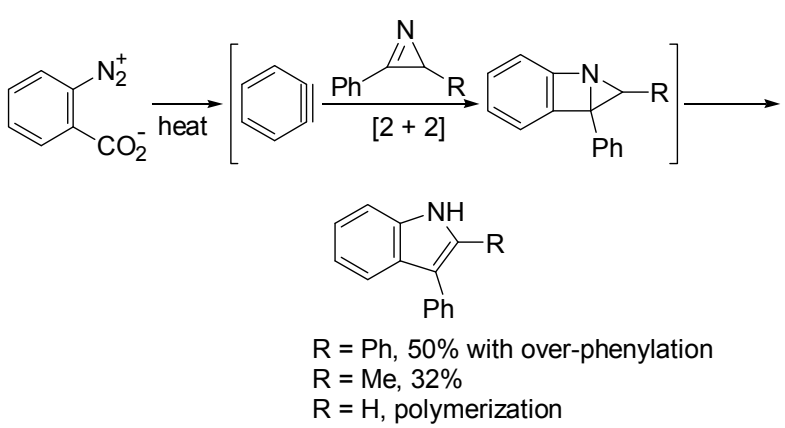

图式 9 苯炔对嗃丙因碳氮双键的插入

Scheme 9 Aryne $\mathrm{C}=\mathrm{N}$ double bond insertion with $2 \mathrm{H}$-azirines

\section{1 苯炔对芳香醛的插入反应}

2004 年, Yoshida 课题组 ${ }^{[19]}$ 报道了两分子苯炔与芳 基醛的三组分反应. 其中，一分子苯炔首先与芳基醛的 
碳氧双键发生插入反应, 生成的氧杂苯并四元环中间体 随后开环, 并与另一分子苯炔发生 $[4+2]$ 反应, 得到氧 杂葱(Scheme 10). 该反应只适用于富电子的芳基醛, 带 有吸电子基的芳醛不能得到这类产品.

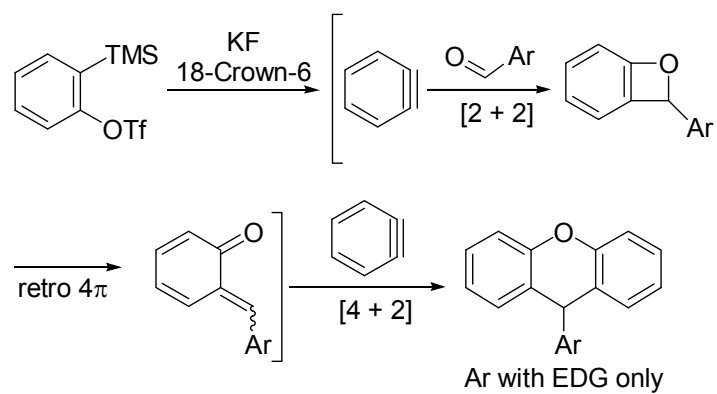

图式 10 苯炔对芳醛碳氧双键的插入/[4+2]环加成串联反应 Scheme 10 Aryne $\mathrm{C}=\mathrm{O}$ double bond insertion/[4+2] cycloaddition sequence with aromatic aldehydes

\section{2 苯炔对甲酰胺的插入反应}

Miyabe 课题组在苯炔与甲酰胺的多组分反应中做 了非常系统的工作. 该反应起始于苯炔对甲酰胺羰基的 插入, 这个过程生成的四元环中间体可以以一种稍微不 同的机理发生开环(Scheme 11), 生成烯胺型邻亚甲基 醌中间体 $\mathbf{5}$, 后者可以以芳基醛亚胺的酚内盐 $\mathbf{5}^{\prime}$ 的共振 式存在. 值得注意的是, 5 和 $\mathbf{5}^{\prime}$ 两个共振式的活性不一 致, 前者主要表现为苄位的亲电性(Michael 反应受体), 可以接受各种亲核试剂的进攻而发生芳构化; 而后者除 芐位的亲电性之外, 还表现出酚氧负离子的亲核性, 可 以与亲电试剂反应. 遗憾的是, 已经报道的此类反应有 两个局限性. 其一是反应只适用于甲酰胺, 乙酰胺得到 的是 $\mathrm{C}=\mathrm{O} \pi$-键插入和 $\mathrm{C}-\mathrm{N} \sigma$-键插入的混合物, 甲酸 酯和碳酸酯等都不能得到类似的产品. 硫代甲酰胺的 $\mathrm{C}=\mathrm{S}$ 双键也不能发生类似反应. 其二是反应大多需要 极大过量的甲酰胺 $(>10$ equiv.), 甚至需要以甲酰胺为 溶剂才能得到较好产率, 限制了其应用价值和合成的可

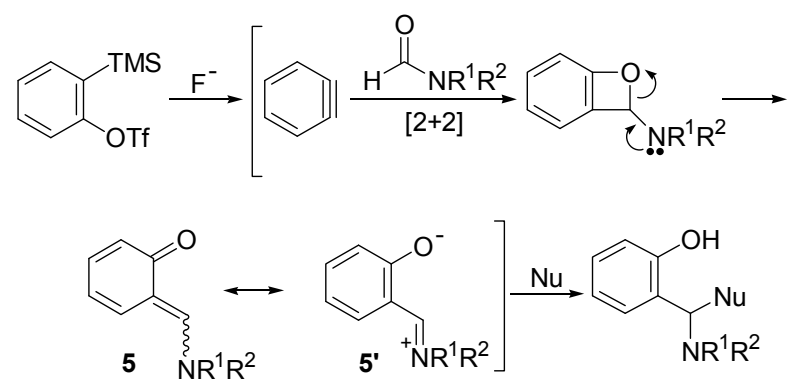

图式 11 苯炔对甲酰胺碳氧双键的插入

Scheme 11 Aryne $\mathrm{C}=\mathrm{O}$ double bond insertion with formamides
操作性. 此外，已报道的此类反应大都是在 3-甲氧基苯 炔上实现的, 无 3-甲氧基时产率大都有所下降并伴随较 为严重的副反应.

2010 年, 该课题组 ${ }^{[20]}$ 首先报道了有机锌试剂作为 亲核第三组分捕获 $\mathbf{5 / 5}$ '的反应，烷基或芳基锌均可得到 较高产率，而格氏试剂只得到复杂的混合物(Scheme 12). 他们 ${ }^{[21]}$ 还用 $\mathrm{Et}_{3} \mathrm{~B}$ 代替锌试剂进行了对照反应，排 除了自由基机理. 除了有机锌试剂以外，水也可以用来 捕获 5/5', 得到水杨醛(Scheme 12). 随后, 该课题组 ${ }^{[22]}$ 发现 $\beta$-羰基酯或 $\beta$-羰基酮也可以作为亲核的第三组分 捕获中间体 5/5'. 值得一提的是, Stoltz 和 Yoshida 等 ${ }^{[23]}$ 早先曾报道过在没有甲酰胺存在时, 苯炔能与 $\beta$-羰基酯 或 $\beta$-羰基酮发生 $\mathrm{C}-\mathrm{C} \sigma$-键插入反应. 但 Miyabe 课题组 发现在以甲酰胺为溶剂, TBAF 为氟源的条件下, 苯炔 与甲酰胺生成 $\mathbf{5} / \mathbf{5}^{\prime}$ 的过程优先发生. 随后, $\mathbf{5} / \mathbf{5}^{\prime}$ '被 $\beta$-羰基 酮/酯的烯醇负离子捕获, 并伴随着一个增环过程生成 色烯骨架. 其中, $\beta$-羰基酮参与的反应生成 $2 H$-色烯 (Scheme 12), $\beta$-羰基酯或 $\beta$-二酯参与的反应生成色烯-2酮(Scheme 12). 除此之外, $\alpha$-位被 $\mathrm{CF}_{3}$ 取代的丙酮和 $\alpha$ 硝基酯也可以参与反应，但产率较低.

最近，该课题组 ${ }^{[24]}$ 又报道了 2 -溴代或 2 -氯代丙二酸 二酯作为第三组分参与的反应. 有趣的是, 二者的反应 性、反应条件和产物均不相同: 2-溴代丙二酸二酯参与 的反应需要加入等物质的量的 $\mathrm{AlMe}_{3}$, 后者原位还原 2溴代丙二酸二酯生成脱溴的烯醇负离子 $\mathbf{6}$, 从而经历和 Scheme 12 一致的过程生成色烯-2-酮(Scheme 13); 而较 难被还原的 2-氯代丙二酸二酯参与的反应需要加入等 物质的量的 $\mathrm{ZnEt}_{2}$, 后者的还原性不足, 只能使前者以 氯代烯醇负离子 7 的形式与 $\mathbf{5 / 5}$ '发生[4+1]环加成, 生 成二氢苯并呋喃衍生物(Scheme 13). 文章还指出, 后一 反应生成的二氢苯并呋喃衍生物可以与过量的 $\mathrm{ZnEt}_{2}$ 进 一步反应经历加成、消除过程生成苯并呋喃.

以上报道中，苯炔插入羰基得到的邻亚甲基醌型中 间体主要参与与亲核试剂的反应, 该中间体参与与亲电 试剂的反应报道较少. 已知的可能案例有两个. 第一个 是 Miyabe 课题组 ${ }^{[24 b]}$ 报道的使用亲电的 $\alpha$-碘代单酯捕获 5/5'的反应. Scheme 14 描述了该反应的两种可能机理. 第一种(path a) 是一个苯炔、甲酰胺、 $\alpha$-碘代酯和水的四 组分反应，其中，水作为亲核试剂先进攻 $\mathbf{5 / 5}$, 生成的 氧负离子再进攻亲电的 $\alpha$-碘代酯, 最后经历缩合过程得 到最终的苯并呋喃. 第二种 (path b) 是由中间体 5 '的酚氧 负离子作为亲核试剂首先进攻 $\alpha$-碘代酯，随后发生缩合 过程. 第二个以 $\mathbf{5}^{\prime}$ 的形式参与后续反应的案例是王彦广 课题组 ${ }^{[25]}$ 报道的以酰基氧作为第三组分的反应. 该反 应的历程和 Scheme 14 中 path b 类似，中间体 $\mathbf{5}^{\prime}$ 的酚 


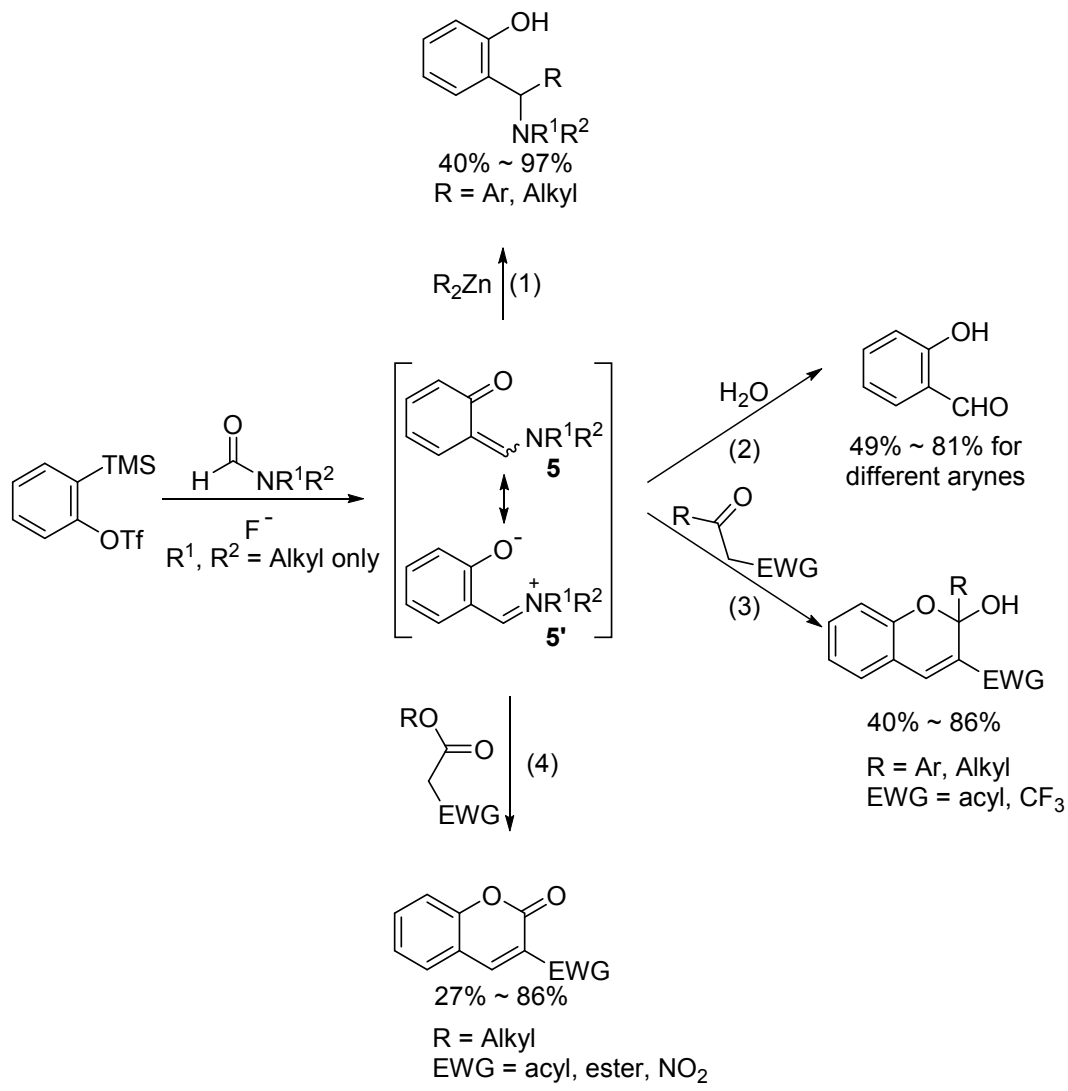

图式 12 中间体 5/5'发生的亲核加成与增环过程

Scheme 12 Nucleophilic addition and annulation processes of intermediate 5/5'

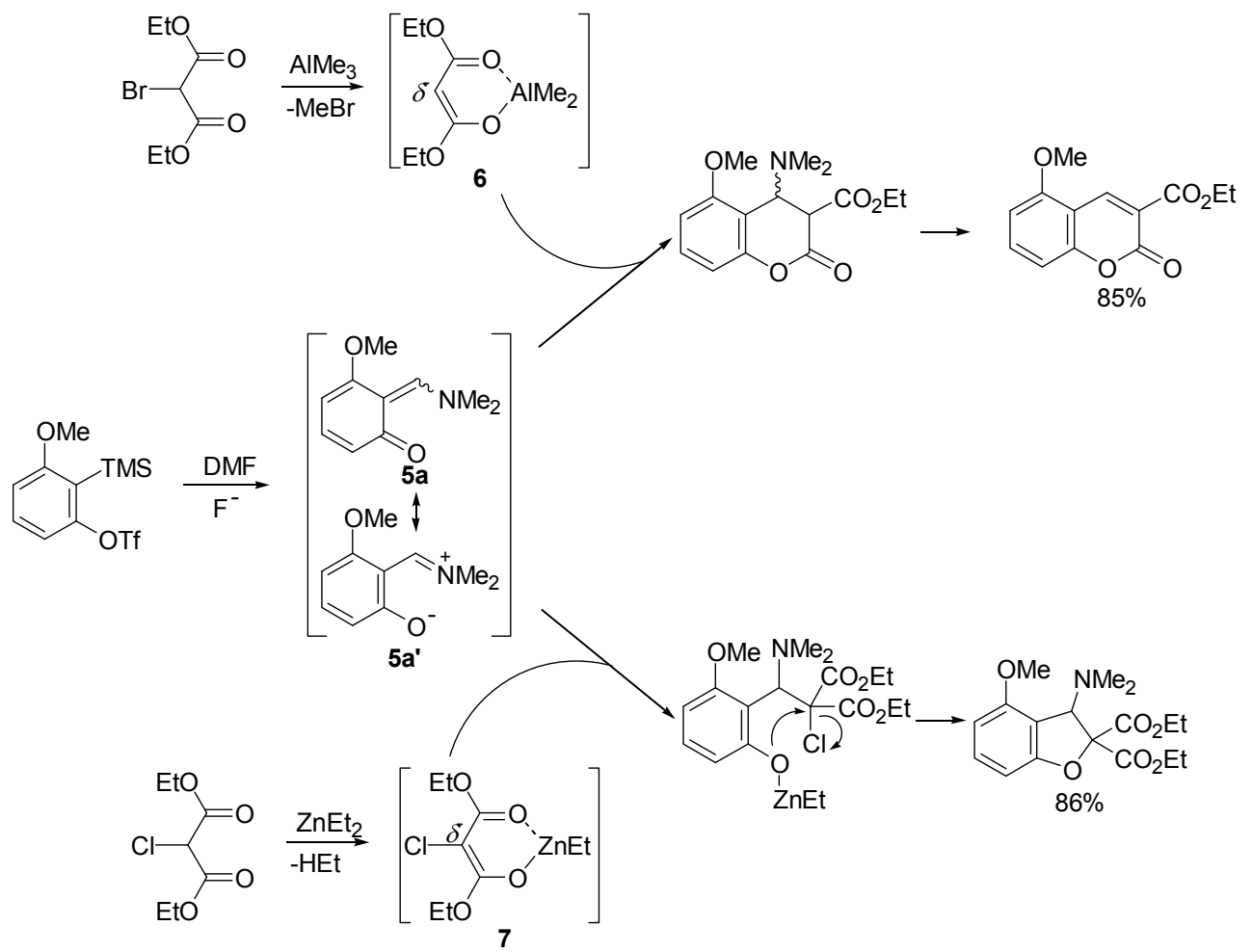

图式 13 中间体 $\mathbf{5} / \mathbf{5}^{\prime}$ 与卤代丙二酸二酯发生的增环过程

Scheme 13 The annulation process of intermediate $\mathbf{5} / \mathbf{5}^{\prime}$ with halomalonates 


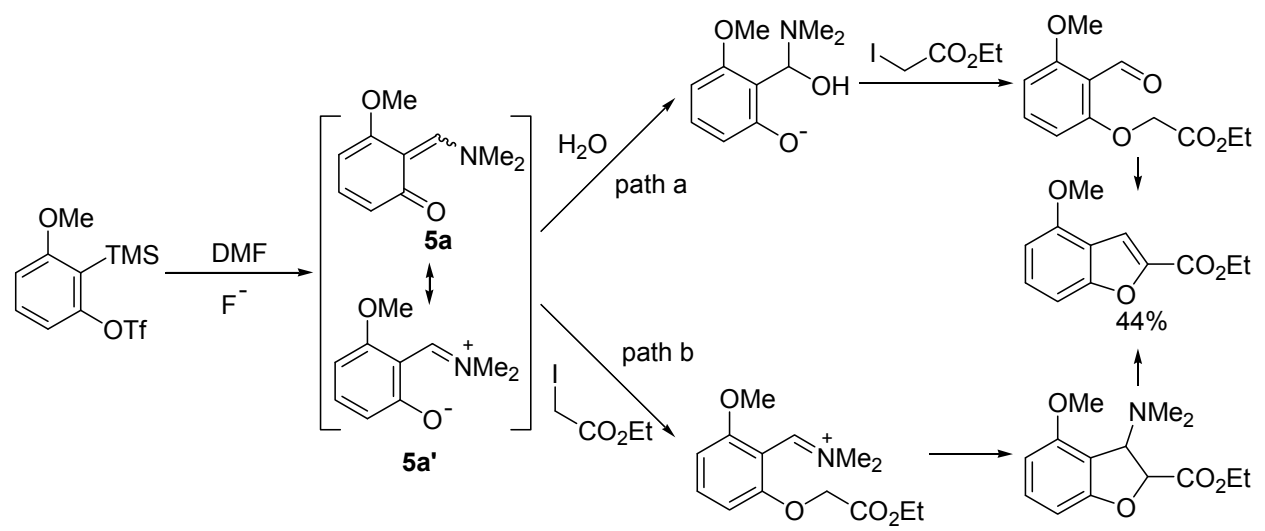

图式 14 中间体 5/5' 与 $\alpha$-碘代酯发生的增环过程

Scheme 14 The annulation process of intermediate $\mathbf{5} / \mathbf{5}^{\prime}$ with $\alpha$-iodoesters

氧负离子作为亲核试剂进攻酰基氰, 离去的氧基又作为 亲核试剂进攻亚胺基(Scheme 15), 实现了邻亚甲基醌 中间体的双官能团化. 这两个报道明确了带有给电子基 的邻亚甲基醌可以以内盐型结构参与反应, 被亲电试剂 捕获, 对类似三组分反应第三组分的范围进行了有意义 的补充.

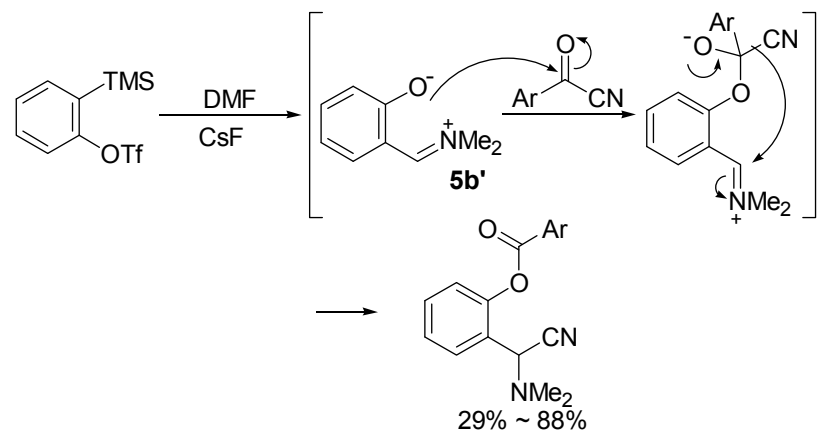

除了上述与亲核试剂、亲电试剂的反应以外，中间 体 5 还可以作为双烯参与 $[4+2]$ 环加成反应. Miyabe 课 题组 ${ }^{[26]}$ 最近报道了邻亚甲基醌中间体 $\mathbf{5}$ 被杂 Diels-Alder 反应捕获的三组分反应. 在该反应中, 丁炔二酸二酯可 以作为亲双烯体和 5 发生 [4+2]环加成生成 $4 H$-色烯衍 生物(Scheme 16). 可惜该反应仅适用于丁炔二酸二酯. 3-位无取代的丙炔酸酯可以反应, 以低产率得到双键移 位的 $2 H$-色烯. 苯丙炔酸酯和缺电子的烯烃(如马来酸二 酯、富马酸二酯和马来酰亚胺)都不能发生类似的反应. 丁炔单酸酯和环状 $\alpha, \beta$-不饱和酮能参与反应, 但不是以 亲双烯体的角色参与环加成反应，而是作为亲核试剂与 5/5'发生亲核加成/增环反应生成三环化合物. 这个报道 的结果虽然显得较为凌乱, 缺乏合成方面的实用意义, 但它对扩展中间体 $\mathbf{5}$ 的捕获反应依然是机理方面的有益 补充.

图式15 中间体 $5^{\prime}$ 与酰基氰发生的双官能团化过程

Scheme 15 Difunctionalization of intermediate 5' with acylcyanides

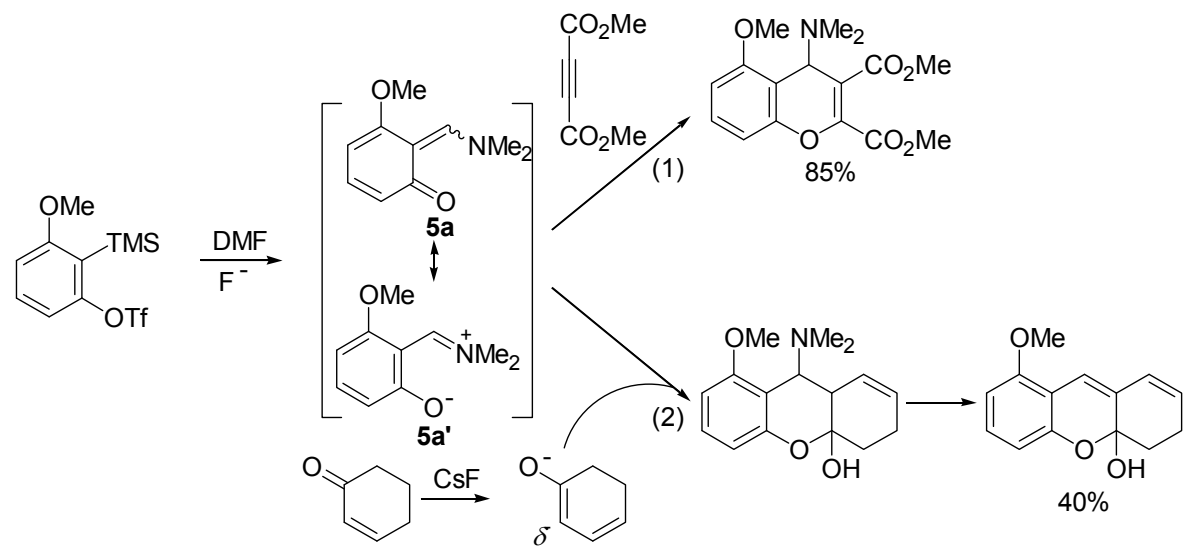

图式 16 中间体 5/5'发生的[4+2]环加成和亲核加成/增环过程

Scheme $16[4+2]$ Cycloaddition and annulation processes of intermediate 5/5' 


\section{3 苯炔对 $\alpha, \beta$-不饱和醛的插入反应}

2012 年, 黄宪课题组 ${ }^{[27]}$ 报道了苯炔与 $\alpha, \beta$-不饱和醛 的反应. 在该反应中, 苯炔首先与醛羰基发生插入反应, 生成的邻亚甲基醌中间体 8 发生分子内 $6 \pi$ 电环合反应 生成 $2 H$-色烯(Scheme 17). 该反应仅限于 $\alpha, \beta$-不饱和醛, $\alpha, \beta$-不饱和酮或酯均不能发生类似反应. 与之形成明显 对比的是, Mead 课题组 ${ }^{[28]}$ 在同一年报道了 $\alpha, \beta$-不饱和醛 /酮亚胺与苯炔的反应. 和不饱和醛发生羰基插入 $/ 6 \pi$ 电 环合不同, 不饱和亚胺与苯炔的反应以杂 Diels-Alder 环 加成反应为主(Scheme 17), 其碳氮双键插入 $/ 6 \pi$ 电环合 过程需要在控制较低温度的情况下分步实现, 且产率很 低. 需要指出的是, 两个课题组使用的苯炔前体是不同 的. 黄宪课题组使用的是 Kobayashi 前体, 而 Mead 课题 组使用的是重氮化的邻氨基苯甲酸.
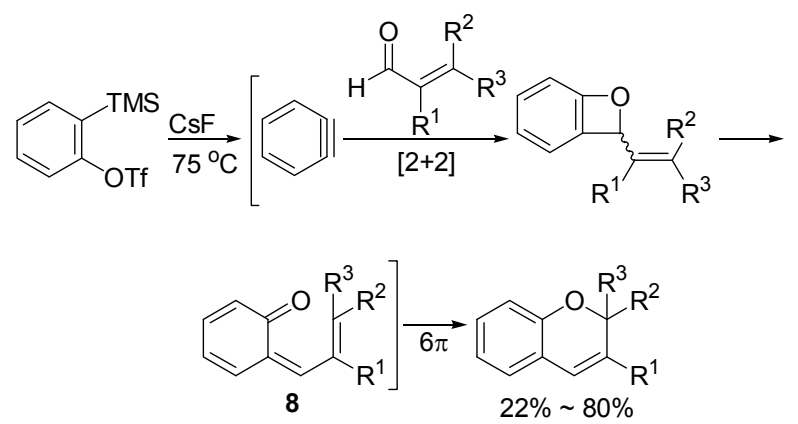

$\mathrm{R}^{1} \sim \mathrm{R}^{3}=\mathrm{H}$, Ar, Alkyl

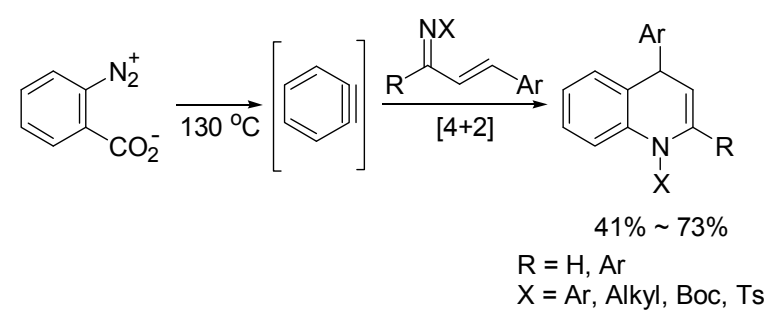

图式 17 苯炔对 $\alpha, \beta$-不饱和醛与其亚胺的不同过程 Scheme 17 Different processes of aryne reaction with $\alpha, \beta$-unsaturated aldehydes and their imine counterpart

\section{4 苯炔对杂原子双键的插入反应}

可以与苯炔发生插入反应的杂原子双键包括 $\mathrm{P}=\mathrm{C}$ 键、 $\mathrm{P}=\mathrm{N}$ 键、 $\mathrm{P}=\mathrm{S}$ 键、 $\mathrm{C}=\mathrm{S}$ 键、 $\mathrm{S}=\mathrm{O}$ 键等. 和 $\mathrm{C}=\mathrm{X}$ 键一样, 这些杂原子双键也需要具备电子极化的特征, 即需要有亲电端和亲核端, 才能顺利与苯炔发生反应.

\section{1 苯炔对含磷双键的插入反应}

含磷双键包括 $\mathrm{P}=\mathrm{C}$ 键、 $\mathrm{P}=\mathrm{N}$ 键、 $\mathrm{P}=\mathrm{S}$ 键, 其中 的磷均为五价, 因此其底物的结构事实上均为叶立德性 质. 与苯炔发生插入反应时, 其碳、氮、硫作为亲核端, 磷作为亲电端.
$\mathrm{P}=\mathrm{C}$ 双键的典型代表是 Wittig 试剂. 苯炔插入 Wittig 试剂 $\mathrm{P}=\mathrm{C}$ 键的反应早在 1964 年即有报道 ${ }^{[29]}$. 有 趣的是, $\mathrm{P}=\mathrm{C}$ 键插入生成的磷杂邻甲基醌型中间体 9 的 活性与上述的类似中间体不同. 它不发生 $6 \pi$ 电环合，而 是发生一个苯基从磷到亚甲基碳原子的 $[1,4]$ 迁移 (Scheme 18). 遗憾的是文章只有一个例子, 没有给出产 率，也没有对该反应进行进一步的研究.

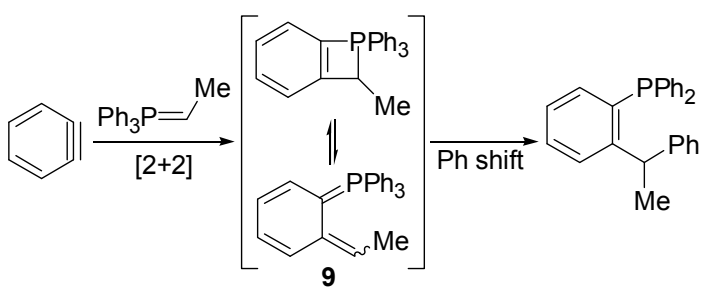

图式 18 苯炔对磷叶立德磷碳双键的插入/苯基迁移串联反应 Scheme 18 Aryne $\mathrm{P}=\mathrm{C}$ double bond insertion/phenyl transfer sequence with a Wittig reagent

除了 $\mathrm{P}=\mathrm{C}$ 键以外, $\mathrm{P}=\mathrm{N} / \mathrm{P}=\mathrm{S}$ 键也可以发生苯炔插 入反应. Alajarin 课题组报道了该反应随底物结构不同 而引出的 3 种不同的历程和不同的产物.

第一种情况的底物为烯基膦亚胺(Scheme 19) ${ }^{[30]}$. 此时苯炔插入形成的中间体 10 发生 $6 \pi$ 电环合生成苯并 六元杂环，后者被溶剂乙腈质子化形成季磷盐产物。该 反应也适用于炔基膦亚胺和炔基膦的硫化物 (Scheme 19 ,), 后者发生的是 $\mathrm{P}=\mathrm{S}$ 键的插入过程. 此反应的整体 机理和结果与 Scheme 17 所示的 $\alpha, \beta$-不饱和醛类似.

第二种情况的底物为烷基和芳基膦亚胺 ${ }^{[31]}$. 这种 情况下 $\mathrm{P}=\mathrm{N}$ 键插入依然会发生, 但生成的中间体 11 不 发生 $6 \pi$ 电环合, 而被溶剂乙腈质子化, 并可能继续与苯 炔反应, 生成 2-氨基苯基季磷盐(Scheme 20). 同样, 该 反应也适用于烷基和芳基膦的硫化物, 发生 $\mathrm{P}=\mathrm{S}$ 键的 插入(Scheme 20).

第三种情况的底物为磷酸亚胺或次磷酸亚胺的甲 酷 ${ }^{[31]}$. 反应在中间体 12 阶段发生了类似 Arbuzov 反应 的 $O$-脱甲基过程, 生成 2-氨基芳基膦的氧化物(Scheme 21). 他们没有报道生成的氨基是否可以如 Scheme 20 所 示继续和苯炔反应. 但是, 反应停留在了膦氧化物阶段 的事实, 至少显示出 $\mathrm{P}=\mathrm{O}$ 双键较 $\mathrm{P}=\mathrm{N} / \mathrm{P}=\mathrm{S}$ 双键更难 以发生苯炔插入反应的结论.

需要指出的是, 上述过程的中间体, 尤其是 11 的 氮/硫原子都表现出了亲核性. 这可能来源于含磷双键 的叶立德性质, 以及相应中间体因此表现出的类似 $\mathbf{5}^{\prime}$ (Scheme 11)的内盐型结构及反应活性 ${ }^{[32]}$. 


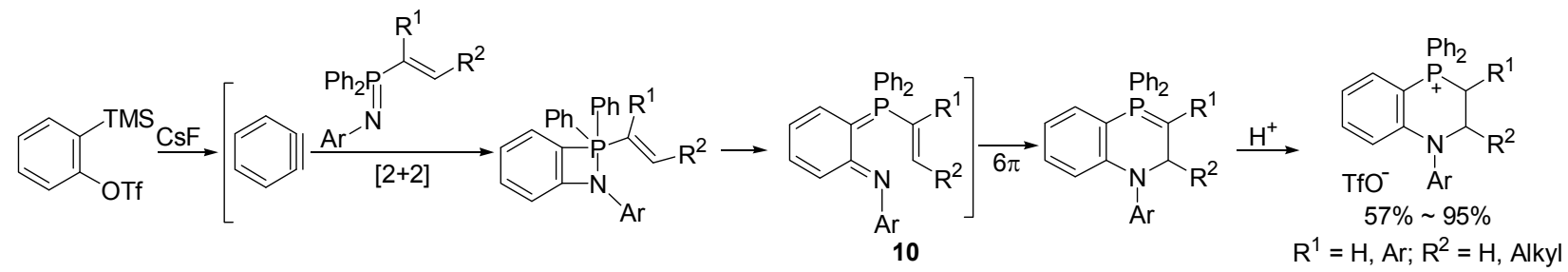<smiles>CCOc1ccccc1C</smiles><smiles>CCPCP(C)CC</smiles><smiles>[X]c1ccccc1Pc1ccccc1</smiles>

图式 19 苯炔对烯基膦亚胺磷氮双键的插入 $/ 6 \pi$ 电环合串联反应

Scheme 19 Aryne $\mathrm{P}=\mathrm{N}$ double bond insertion $/ 6 \pi$ electrocyclization sequence with $P$-vinyl iminophosphoranes

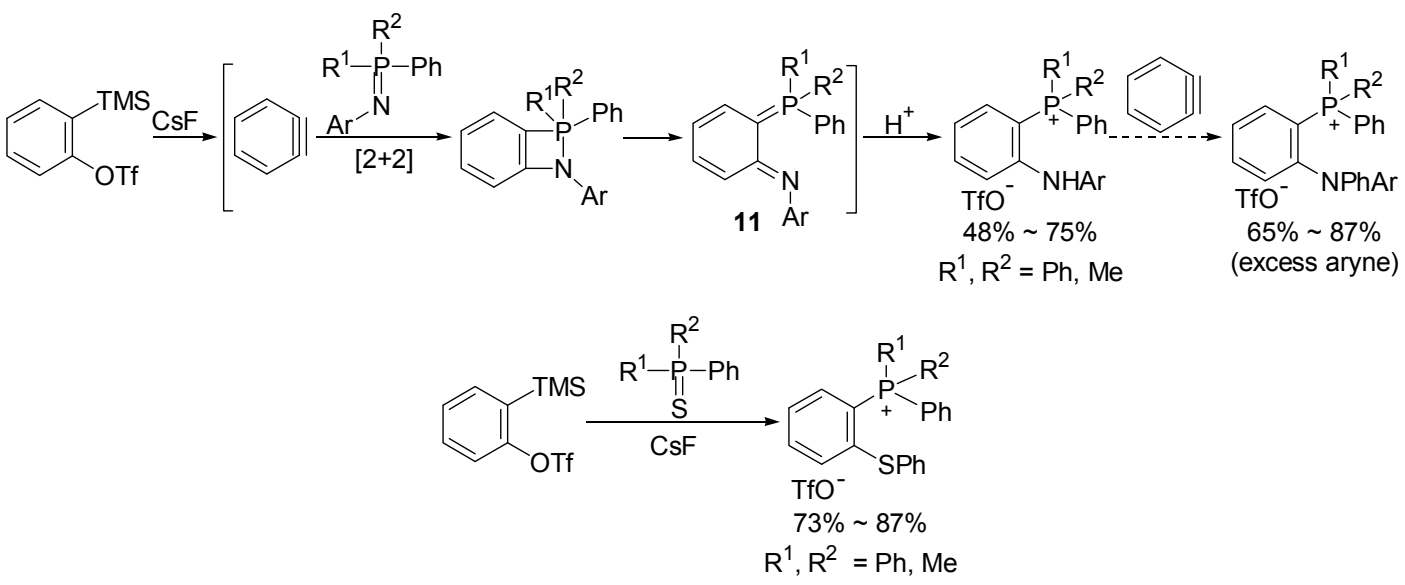

图式 20 苯炔对烷基/芳基膦亚胺磷氮双键的插入引起的串联反应

Scheme 20 Aryne $\mathrm{P}=\mathrm{N}$ double bond insertion sequence with $P$-alkyl/aryl iminophosphoranes

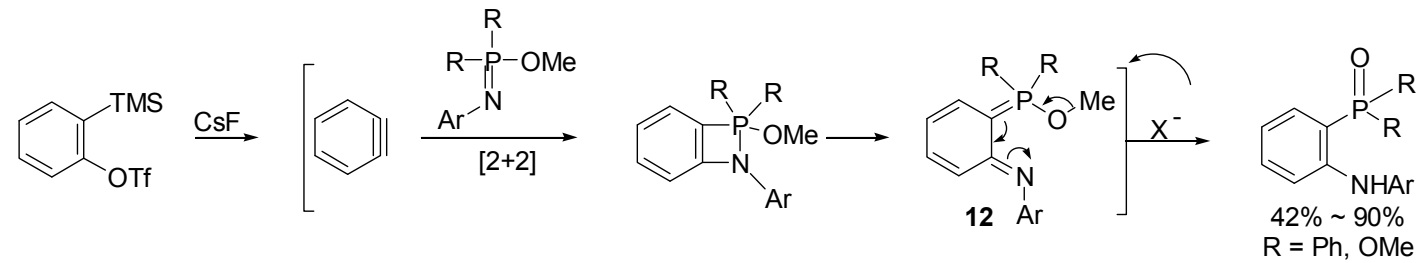

图式 21 苯炔对磷酸亚胺酯磷氮双键的插入/去甲基串联反应

Scheme 21 Aryne $\mathrm{P}=\mathrm{N}$ double bond insertion/demethylation sequence with $P$-methoxy iminophosphoranes

\section{2 苯炔对含硫双键的插入反应}

含硫双键中, $\mathrm{P}=\mathrm{S}$ 键与苯炔的插入反应前已述及, 其它能与苯炔反应的含硫双键包括硫艮的 $\mathrm{C}=\mathrm{S}$ 和亚砜 的 $\mathrm{S}=\mathrm{O}$ 双键. 前者的硫作为亲核端，后者的氧作为亲 核端.

苯炔对硫脲 $\mathrm{C}=\mathrm{S}$ 键的插入如 Scheme 22 所示 ${ }^{[33]}$. 这个反应从严格意义上说是一个形式 $\mathrm{C}=\mathrm{S}$ 双键的插入, 因为该过程也可以被理解为苯炔对 $\mathrm{C}-\mathrm{S}$ 单键的插入. 在后一种理解中, 硫腿被视作以共振式异硫脲两性离子 的形式进攻苯炔, 形成的苯基负离子再对异硫脲进行分
子内的加成/消除生成中间体 13. 整个历程相当于苯炔 插入了异硫脲两性离子的 $\mathrm{C}-\mathrm{S}$ 单键中. 中间体 13 的结 构更像是内盐型的 $\mathbf{5}^{\prime}$ (Scheme 11), 而不是邻亚甲基醌 型的 5, 故同 5'一样表现出亲核性。

苯炔对亚砜 $\mathrm{S}=\mathrm{O}$ 键的插入反应由肖文精课题组 ${ }^{[34]}$ 在 2014 年报道(Scheme 23). 需要指出的是, 和含磷化 合物一样, 亚砜也是叶立德型的化合物. 因此, 苯炔插 入亚砜 $\mathrm{S}=\mathrm{O}$ 键生成的中间体 $\mathbf{1 4}$ 也体现出内盐型的结 构，表现出亲核的性质。事实上，该课题组报道的亚砜 插入反应，使用的第三组分是亲电的 $\alpha$-溴代羰基化合物 


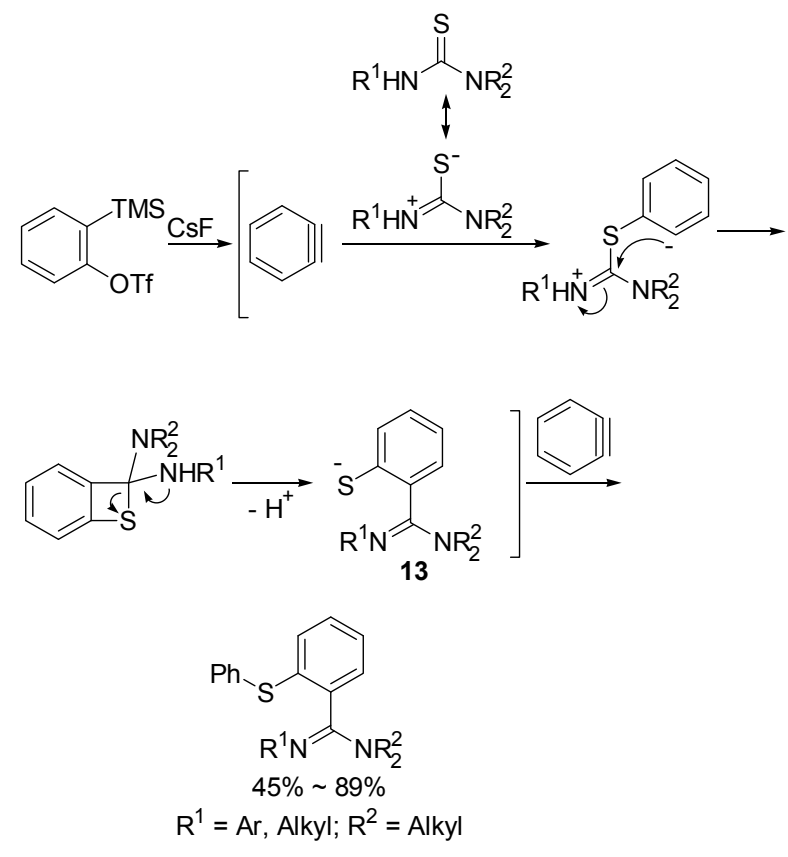

图式 22 苯炔对硫脲碳硫双键的插入/苯基化串联反应

Scheme 22 Aryne $\mathrm{C}=\mathrm{S}$ double bond insertion/phenylation sequence with thioureas

和芐溴类化合物, 其整体机理与 Scheme 14 中 path b 类 似.

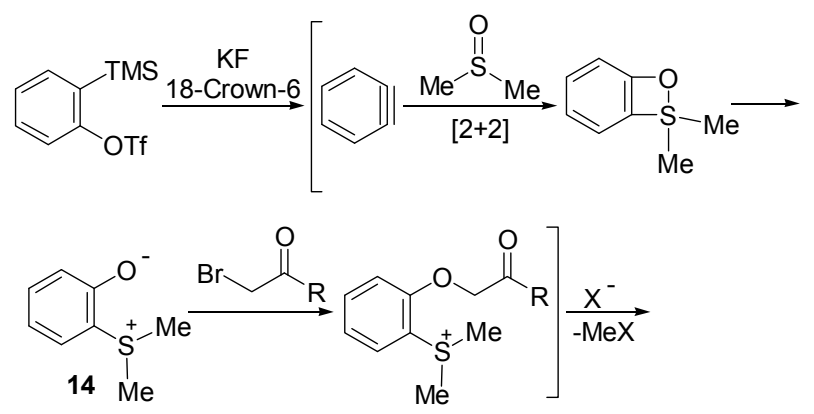

$$
R=A r, A l k y l, O R, N_{2}
$$

图式 23 苯炔对亚砜硫氧双键的插入/烷基化串联反应 Scheme 23 Aryne $\mathrm{S}=\mathrm{O}$ double bond insertion/alkylation sequence with sulfoxides

\section{3 苯炔对氮氧双键的插入反应}

2013 年, Studer 课题组 ${ }^{[35]}$ 报道了苯炔与亚硝基化合 物生成咔唑的反应. 该反应的机理尚不明确, 不过他们 提出的机理涉及到了一个苯炔对 $\mathrm{N}=\mathrm{O}$ 键的插入过程 (Scheme 24). 该过程生成的邻苯醌半亚胺中间体 15 没 有发生 $6 \pi$ 电环合, 而是发生了苯基对羰基的亲核加成. 作者提出的后续 $\mathrm{OH}$ 的消去过程有些令人费解, 因为进
攻 $\mathrm{OH}$ 的亲核试剂必须是还原性的，而反应体系中并不 存在还原剂. 因此, $\mathrm{N}=\mathrm{O}$ 插入过程是否有充足的证据 支持尚存疑问. 不过该反应作为一种合成咔唑的新方法 还是有其价值的.

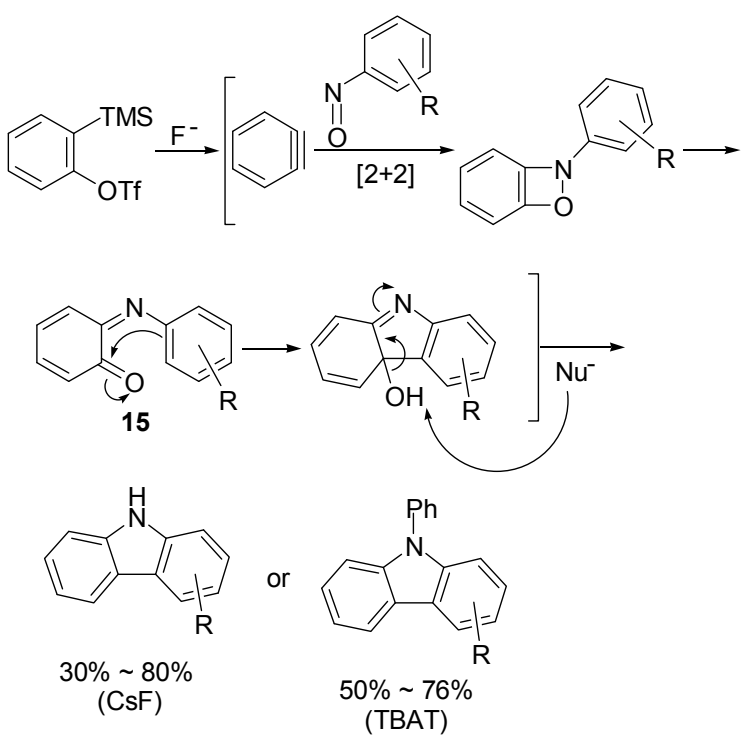

图式 24 苯炔对亚硝基化合物氮氧双键的插入及生成咔唑的 反应

Scheme 24 Aryne $\mathrm{N}=\mathrm{O}$ double bond insertion with nitroso compounds affording carbazoles

\section{5 结论与展望}

苯炔作为一种重要的有机活性中间体，早期的研究 主要集中于反应机理方面. Kobayashi 前体的出现及广 泛使用，使苯炔作为有机合成的分子砌块在最近十年重 新焕发了生机. 苯炔对双键的插入反应是苯炔化学的新 方向之一，在反应机理、合成应用方面具有良好的前景. 有趣的是，邻亚甲基醌类也是重要的有机活性中间体， 在合成上同样被广泛研究. 苯炔的双键插入反应, 恰恰 能将这两类活性中间体有机的联系起来，从一个有机活 性中间体，生成另一个有机活性中间体．可以预见，通 过联系二者，并根据其反应活性的差别设计后续进程， 将是下一阶段研究的重点.

\section{References}

[1] For reviews, see:

(a) Pellissier, H.; Santelli, M. Tetrahedron 2003, 59, 701.

(b) Wenk, H. H.; Winkler, M.; Sander, W. Angew. Chem., Int. Ed. 2003, 42, 502.

(c) Bhunia, A.; Yetra, S. R.; Biju, A. T. Chem. Soc. Rev. 2012, 41, 3140.

(d) Wu, C.-R.; Shi, F. Asian J. Org. Chem. 2013, 2, 116.

(e) Dubrovskiy, A. V.; Markina, N. A.; Larock, R. C. Org. Biomol. Chem. 2013, 11, 191

(f) Gampe, C. M.; Carreira, E. M. Angew. Chem., Int. Ed. 2012, 51, 3766. 
(g) Tadross, P. M.; Stoltz, B. M. Chem. Rev. 2012, 112, 3550.

[2] Himeshima, Y.; Sonoda, T.; Kobayashi, H. Chem. Lett. 1983, 12, 1211.

[3] For reviews of aryne insertion into $\sigma$-bonds, see:

(a) Pena, D.; Perez, D.; Guitian, E. Angew. Chem., Int. Ed. 2006, 45, 3579 .

(b) Yoshida, H.; Ohshita, J.; Kunai, A. Bull. Chem. Soc. Jpn. 2010, 83, 199.

[4] For reviews of $o$-quinomethides and related intermediates, see:

(a) Zheng, R.-S.; Zhu, S.-F. Chin. J. Org. Chem. 2014, 34, 1322 (in Chinese).

(郑若山, 祝诗发, 有机化学, 2014, 34, 1322.)

(b) Segura, J. L.; Martin, N. Chem. Rev. 1999, 99, 3199.

(c) Collier, S. J.; Storr, R. C. In Progress in Heterocyclic Chemistry, Vol. 10, Eds.: Gribble, G. W.; Gilchrist, T. L., Elsevier Science, Oxford, UK, 1998, pp. 25 48.

[5] Crews, P.; Beard, J. J. Org. Chem. 1973, 38, 522.

[6] Caubère, P. Top. Curr. Chem. 1978, 73, 49.

[7] (a) Hamura, T.; Ibusuki, Y.; Sato, K.; Matsumoto, T.; Osamura, Y.; Suzuki, K. Org. Lett. 2013, 15, 3551.

(b) Hamura, T.; Ibusuki, Y.; Uekusa, H.; Matsumoto, T.; Suzuki, K. J. Am. Chem. Soc. 2006, 128, 3534.

(c) Hamura, T.; Ibusuki, Y.; Uekusa, H.; Matsumoto, T.; Siegel, J. S.; Baldridge, K. K.; Suzuki, K. J. Am. Chem. Soc. 2006, 128, 10032.

(d) Hamura, T.; Arisawa, T.; Matsumoto, T.; Suzuki, K. Angew. Chem., Int. Ed. 2006, 45, 6842.

[8] (a) Gingrich, H. L.; Huang, Q.; Morales, A. L.; Jones, M. J. Org. Chem. 1992, 57, 3803.

(b) Heaney, H.; Ley, S. V. J. Chem. Soc., Perkin Trans. 1 1974, 2693.

[9] Feltenberger, J. B.; Hayashi, R.; Tang, Y.; Babiash, E. S. C.; Hsung, R. P. Org. Lett. 2009, 11, 3666.

[10] Ma, Z.-X.; Feltenberger, J. B.; Hsung, R. P. Org. Lett. 2012, 14, 2742.

[11] Ramtohul, Y. K.; Chartrand, A. Org. Lett. 2007, 9, 1029.

[12] Li, R.; Wang, X.-M.; Wei, Z.-B.; Wu, C.-R.; Shi, F. Org. Lett. 2013, $15,4366$.

[13] Li, R.; Tang, H.-R.; Fu, H.-X.; Wang, X.-M.; Wu, C.-R.; Wu, C.; Shi, F. J. Org. Chem. 2014, 79, 1344.

[14] Nakayama, J.; Midorikawa, H.; Yoshida, M. Bull. Chem. Soc. Jpn.
1975, 48, 1063.

[15] Aly, A. A.; Mohamed, N. K.; Hassan, A. A.; Mourad, A.-F. E. Tetrahedron 1999, 55, 1111.

[16] Yoshida, H.; Fukushima, H.; Ohshita, J.; Kunai, A. J. Am. Chem. Soc. 2006, 128, 11040.

[17] Zhou, Y.; Chi, Y.; Zhao, F.; Zhang, W.-X.; Xi, Z.-F. Chem. Eur. J. 2014, 20, 2463.

[18] Nair, V.; Kim, K. H. J. Org. Chem. 1975, 40, 3784.

[19] Yoshida, H.; Watanabe, M.; Fukushima, H.; Ohshita, J.; Kunai, A. Org. Lett. 2004, 6, 4049.

[20] Yoshioka, E.; Kohtani, S.; Miyabe, H. Org. Lett. 2010, 12, 1956.

[21] Yoshioka, E.; Miyabe, H. Tetrahedron 2012, 68, 179.

[22] Yoshioka, E.; Kohtani, S.; Miyabe, H. Angew. Chem., Int. Ed. 2011, 50,6638 .

[23] (a) Tambar, U. K.; Stoltz, B. M. J. Am. Chem. Soc. 2005, 127, 5340. (b) Yoshida, H.; Watanabe, M.; Ohshita, J.; Kunai, A. Chem. Commun. 2005, 3292.

[24] (a) Yoshioka, E.; Tanaka, H.; Kohtani, S.; Miyabe, H. Org. Lett. 2013, 15, 3938.

(b) Yoshioka, E.; Kohtani, S.; Miyabe, H. Molecules 2014, 19, 863.

[25] Zhou, C.; Wang, J.; Jin, J.-S.; Lu, P.; Wang Y.-G. Eur. J. Org. Chem. 2014, 1832.

[26] Yoshioka, E.; Tamenaga, H.; Miyabe, H. Tetrahedron Lett. 2014, $55,1402$.

[27] Zhang, T.-X.; Huang, X.; Wu, L.-L. Eur. J. Org. Chem. 2012, 3507.

[28] Stokes, S.; Bekkam, M.; Rupp, M.; Mead, K. T. Synlett 2012, 23, 389.

[29] Zbiral, E. Tetrahedron Lett. 1964, 5, 3963.

[30] Alajarin, M.; Lopez-Leonardo, C.; Raja, R.; Orenes, R.-A. Org. Lett. 2011, 13, 5668.

[31] Lopez-Leonardo, C.; Raja, R.; López-Ortiz, F.; Águila-Sánchez, M. A. D.; Alajarin, M. Eur. J. Org. Chem. 2014, 1084.

[32] It is possible that the ring opening of these benzannulated 4-membered ring intermediates is not retro- $4 \pi$ electrocyclization, but a simple heterolytic $\mathrm{P}-\mathrm{X}$ bond cleavage, due to the structure and orientation of pentavalent phosphorous atoms. Biswas, K.; Greaney, M. F. Org. Lett. 2011, 13, 4946.

[33] Liu, F.-L.; Chen, J.-R.; Zou, Y.-Q.; Wei, Q.; Xiao, W.-J. Org. Lett. 2014, 16, 3768.

[34] Chakrabarty, S.; Chatterjee, I.; Tebben, L.; Studer, A. Angew. Chem., Int. Ed. 2013, 52, 1. 